\title{
Meta-analysis and systematic review of factors biasing the observed prevalence of congenitally missing teeth in permanent dentition excluding third molars
}

\author{
Vahid Rakhshan
}

\begin{abstract}
No meta-analyses or systematic reviews have been conducted to evaluate numerous potential biasing factors contributing to the controversial results on congenitally missing teeth (CMT). We aimed to perform a rather comprehensive meta-analysis and systematic review on this subject. A thorough search was performed during September 2012 until April 2013 to find the available literature regarding CMT prevalence. Besides qualitatively discussing the literature, the meta-sample homogeneity, publication bias, and the effects of sample type, sample size, minimum and maximum ages of included subjects, gender imbalances, and scientific credit of the publishing journals on the reported CMT prevalence were statistically analyzed using Q-test, Egger regression, Spearman coefficient, Kruskal-Wallis, Welch $t$ test $(a=0.05)$, and Mann-Whitney $U$ test $(a=0.016, a=0.007)$. A total of 111 reports were collected. Metadata were heterogeneous $(P=0.000)$. There was not a significant publication bias (Egger Regression $P=0.073$ ). Prevalence rates differed in different types of populations (Kruskal-Wallis $P=0.001$ ). Studies on orthodontic patients might report slightly (about $1 \%$ ) higher prevalence $(P=0.009$, corrected $a=0.016$ ). Non-orthodontic dental patients showed a significant 2\% decline $[P=0.007$ (Mann-Whitney U)]. Enrolling more males in researches might significantly reduce the observed prevalence (Spearman $\rho=-0.407, P=0.001$ ). Studies with higher minimums of subjects' age showed always slightly less CMT prevalence. This reached about $-1.6 \%$ around the ages 10 to 13 and was significant for ages 10 to 12 (Welch $t$ test $P<0.05$ ). There seems to be no limit over the maximum age (Welch $t$ test $P>0.2$ ). Studies' sample sizes were correlated negatively with CMT prevalence ( $\rho=-0.250, P=0.009)$. It was not verified whether higher CMT rates have better chances of being published $(\rho=$ $0.132, P=0.177)$. CMT definition should be unified. Samples should be sex-balanced. Enrolling both orthodontic and dental patients in similar proportions might be preferable over sampling from each of those groups. Sampling from children over 12 years seems advantageous. Two or more observers should examine larger samples to reduce the false negative error tied with such samples.
\end{abstract}

Keywords: Congenitally missing teeth (hypodontia); Permanent dentition; Prevalence; Sources of bias in the literature

Correspondence: vahid.rakhshan@gmail.com

Department of Dental Anatomy and Morphology, Dental Branch,

Islamic Azad University, PO Box 19585-175, Tehran, Iran 


\section{Review}

Introduction

Congenital missing of teeth (CMT) or dental agenesis is a common dental abnormality, in which some dental buds fail to develop, leaving an empty space in the arch which causes numerous complications [1-19]. In most countries, out of every 10 to 20 individuals, at least one suffers from agenesis of at least one or two permanent teeth [1,3-13,16-109]. It is of importance since not only it is very frequent (as the most common dental anomaly) [1-14], but also it needs difficult and expensive treatments $[19,105,110,111]$.

Considering the very high prevalence of CMT [1-14], its serious complications on esthetic and function [2-4,15-19,56,75,77,83,86,89,97,100,105,112-117], and its challenging and costly multidisciplinary treatments $[19,105,110,111]$, studying it seems necessary for many fields. These involve public health, health insurance companies, anthropology, and of course multidisciplinary clinical practice (orthodontics, prosthodontics, pediatric dentistry, surgery, and general dentistry) $[40,105,111,117,118]$.

The results pertaining to CMT are quite controversial. Although ethnicity accounts for a part of the debate [117] (V Rakhshan, unpublished work), a major source of dispute is the existence of different biasing factors in different reports. For example, enrolling younger subjects might increase the chance of encountering 'delayed' tooth eruptions and mistakenly counting the empty spaces as CMT $[18,117]$. Additionally, it is possible that researchers might tend to report the lower CMT prevalence in larger samples and vice versa $[18,117]$. These and other biasing factors should be determined and avoided. Nevertheless, only the aforementioned two examples are meta-analyzed before, and in a small pool of 33 studies [117]. That meta-analysis confirmed the role of sample size but did not find any differences between studies with minimum ages of subjects older or younger than 7 years. They did not evaluate any other minimum ages or address the potential lack of test power due to their small sample. No other biasing factors have been analyzed thus far.

Moreover, recent studies are limited to carry out the sampling almost only from orthodontic and dental patients. This is possibly due to ethical concerns tied to X-ray exposure without any treatment need $[18,116]$. Such samples are assumed to result in overestimation of CMT. However, it is not known whether this assumption is correct [86]. Besides, many studies do not sample an equal number of males and females. Females might somehow show higher CMT prevalence $[10,11,17,35,36,50,82,83,91,100,117,119]$ (V Rakhshan, unpublished work). Therefore, a question is whether enrolling more females can noticeably bias the CMT result (and if so, to which extent). Another possibility is that older patients might not remember their history of extraction, and therefore some extracted teeth might be considered as missing. Knowledge of the effects of these factors is of importance. However, no meta-analyses, systematic reviews, or even narrative reviews have explored these. The literature consists only of two rather narrow-scoped, small-sampled meta-analyses and two partially narrative literature reviews on CMT $[115,117,120]$. Hence, the aim of this study was to address the potential sources of bias of CMT prevalence, using more comprehensive search strategies and a larger sample.

\section{Materials and methods}

During September 2012 until April 2013, the author extensively searched for the keywords 'congenital missing of teeth', 'CMT', 'hypodontia', 'oligodontia', 'anodontia', 'agenesis', and 'prevalence' [117], and combination of these words as well as their synonyms (for example, replacing 'missing' with 'absence,' 'absent', etc.; Table 1). Three Internet search engines [Pubmed, Thomson Reuters ISI Web of Science (WoS), and Google Scholar] were used by the author to search for relevant scientific articles (V Rakhshan, unpublished work).

Reports dealing with patients suffering from craniofacial syndromes or developmental disorders were excluded. Those including only primary dentition were as well excluded. The reports taking the rates of third molar missing cases (without presenting any information to filter third molars out) were excluded (V Rakhshan, unpublished work).

The inclusion criteria were as follows:

- The presence of an English abstract or an abstract readable by the author; or when other studies cited

\section{Table 1 Number of search results}

\begin{tabular}{|c|c|c|c|c|}
\hline Keyword & Pubmed & $\begin{array}{l}\text { Web of } \\
\text { Science }\end{array}$ & $\begin{array}{l}\text { Google } \\
\text { Scholar }\end{array}$ & Total \\
\hline $\begin{array}{l}\text { Variations of 'congenitally } \\
\text { missing teeth }{ }^{a \prime}\end{array}$ & 399 & 95 & 3,133 & 3,627 \\
\hline $\begin{array}{l}\text { Hypodontia or anodontia or } \\
\text { oligodontia }\end{array}$ & 3,345 & 940 & 12,300 & 16,585 \\
\hline $\begin{array}{l}\text { 'Dental aplasia' or 'dental } \\
\text { agenesis' or 'tooth aplasia' } \\
\text { or 'tooth agenesis' }\end{array}$ & 353 & 398 & 3,300 & 4,051 \\
\hline $\begin{array}{l}\text { Congenitally missing teeth } \\
\text { and prevalence }\end{array}$ & 102 & 27 & 1,630 & 1,759 \\
\hline $\begin{array}{l}\text { (Hypodontia or anodontia or } \\
\text { oligodontia) and prevalence }\end{array}$ & 490 & 170 & 3,560 & 4,220 \\
\hline $\begin{array}{l}\text { (Dental aplasia or dental } \\
\text { agenesis or tooth aplasia } \\
\text { or tooth agenesis) and } \\
\text { prevalence }\end{array}$ & 100 & 106 & 1,560 & 1,766 \\
\hline Total & 4,789 & 1,736 & 25,483 & 32,008 \\
\hline
\end{tabular}

ancluding the search results for congenital missing of teeth, congenital absence of teeth, and congenitally absent teeth. 
local papers and provided useful information from earlier non-English papers on CMT in permanent dentition excluding third molars. The articles cited within the full texts were used after making sure that they meet the inclusion criteria.

- The sample was representative of the underlying general population.

- Diagnosis of dental agenesis was based on a radiographic examination (if not stated otherwise in them or in the citing articles).

- Agenesis of third molars was excluded [117].

- Data pertaining to at least one of the biasing factors of interest alongside CMT prevalence were present (V Rakhshan, unpublished work).

Not all the studies contained all the information simultaneously. As far as at least the prevalence and one biasing factor were reported by a study, it was used in this summary.

The texts of all the available full articles and the abstracts were read carefully by the author. Whenever the necessary data were available (regardless of analyses performed by articles' authors), all the percentages were recalculated. Raw data of one of them were inconsistent, as the two tables presenting the raw data did not match completely [88]. Every available English full text on CMT excluding third molars was read for at least twice. If there was a full text in another language, collecting any useful data piece was tried by means of translators or by digging for the presented numbers or English figure legends, etc. within the article. Some of those articles referred to other studies or reported briefly the previous studies. After making sure that those previous studies do not include third molars (or if they do, it is possible for us to filter or recalculate only information regarding hypodontia excluding third molars), they were included in this summary. Whenever it is possible to recover the raw data from the information, the percentages presented were recalculated and at many points fixed before reporting. Also, many studies had not reported some of the key elements. If possible, their raw data were carefully recovered from the combination of their text, graphs, and tables (V Rakhshan, unpublished work).

\section{Statistical analysis}

The reported prevalence rates in epidemiological studies were compared with those of orthodontic or dental patients, using a Kruskal-Wallis test and a Mann-Whitney $U$ test. The level of significance was adjusted for the Mann-Whitney $U$ test to 0.016, using the Bonferroni correction method for multiple comparisons. The association of publication year with reported CMT percentages was assessed in the literature and in the literature on Caucasians only, using a Spearman correlation coefficient. Also, the correlation between CMT prevalence and the ratio of enrolled male and female subjects in different studies was assessed using a Spearman coefficient. The Spearman coefficient was also used to analyze the potential association of sample size and CMT prevalence. Additionally, the scientific credit of each article was determined by checking its abstraction in Pubmed and Web of Science databases or both (the score 0 for none, 1 for each, and 2 for both); the correlation between the CMT and scores of the articles was evaluated using the Spearman coefficient. The potentially biasing role of minimum and maximum ages of enrolled subjects in different studies was assessed using the Spearman correlation coefficient. We tried to find also any cutoff age after which a significant decrease in CMT could be possibly observed. This was performed by comparing studies with minimum ages less or greater than each cutoff using a Welch $t$ test. The same test was used in the same fashion to possibly find a cutoff point for the maximum age.

\section{Results}

About 24,000 studies were initially found via various search engines which this reduced to about 8,000 more relevant results (Table 1 ) and then to about 2,500 studies without counting the repetitions in different search engines. Searching was updated during the study period to find newly emerged articles, and one new relevant study was published in March 2013. The excluded studies were the duplicated ones (in different search websites), those with no reference to the exclusion of third molars or syndromes, or those pertaining to other aspects of CMT without presenting at least CMT prevalence in permanent dentition and at least one biasing factor. If at least they had graphs or tables from which the CMT prevalence could be recovered and/or the data allowed us to exclude third molars and syndromes, the prevalence would be calculated manually. All the procedures were done for at least twice by one examiner (and for some articles, more than two times). Finally, 111 reports were included in this review (Table 2) [1,3-13,16-109,121] (V Rakhshan, unpublished work).

A single study was published in two different journals (one indexed in Pubmed and the other not indexed in any accredited databases), in the same year, without showing any noticeable difference in the content (thus both were considered as a single report) [95,122]. The sample of Gabris et al. [78] seemed to be used as a subsample in their other study [85], although it is not known for sure as they did not suggest it. Syndrome cases were removed by the author from the study of Galluccio and Pilotto [87]. Cleft palate cases were excluded by the author, and the prevalence was recalculated for the study of Behr et al. [105]; however, four patients among their remaining cases were syndromic. 
Table 2 The reported frequencies on missing of all permanent teeth except the third molars

\begin{tabular}{|c|c|c|c|c|c|c|c|c|c|c|c|}
\hline Year & Country & Type & Prevalence & Year & Country & Type & Prevalence & Year & Country & Type & Prevalence \\
\hline 1936 & Switzerland & SC & 3.4 & 1974 & Canada & SC & 7.4 & 2001 & Kenya & OP & 6.3 \\
\hline 1939 & - & - & 2.3 & 1976 & Sweden & SC & 7.4 & 2001 & Hungary & $\mathrm{OP}$ & 15.7 \\
\hline 1943 & USA & - & 2.8 & 1977 & Iceland & SC & 7.9 & 2001 & Korea & SC & 8.0 \\
\hline 1949 & Japan & St & 15.9 & 1977 & Sweden & SC & 7.4 & 2002 & Norway & PuDP & 4.5 \\
\hline 1951 & Japan & SC & 5.6 & 1977 & Japan & - & 8.6 & 2002 & Iraq & OP & 8.9 \\
\hline 1954 & Japan & SC & 8.7 & 1979 & USA & SC & 7.4 & 2002 & S Arabia & PeDP & 3.6 \\
\hline 1955 & Japan & DS & 1.4 & 1980 & Denmark & SC & 7.8 & 2003 & Mexico & $\mathrm{OP}$ & 2.7 \\
\hline 1956 & Sweden & SC & 6.1 & 1980 & Denmark & SC & 7.7 & 2005 & Slovenia & OP & 11.3 \\
\hline 1956 & USA & DP & 3.7 & 1987 & Hong-Kong & SC & 6.9 & 2006 & Japan & OP & 10.1 \\
\hline 1959 & Sweden & - & 7.4 & 1988 & Japan & $\mathrm{OP}$ & 9.9 & 2006 & Jordan & $\mathrm{DP}$ & 5.5 \\
\hline 1961 & USA & $\mathrm{DP}$ & 5.2 & 1989 & Malaysia & SC & 2.8 & 2006 & Hungary & OP/PeDP & 14.7 \\
\hline 1963 & Norway & SC & 4.5 & 1989 & Australia & $\mathrm{DP}$ & 6.4 & 2007 & Turkey & $\mathrm{OP}$ & 7.5 \\
\hline 1963 & Austria & SC & 9.6 & 1989 & Italy & $\mathrm{DP}$ & 5.2 & 2007 & Turkey & $\mathrm{OP}$ & 2.8 \\
\hline 1963 & Japan & SC & 6.6 & 1989 & USA & PeDP & 7.8 & 2008 & Italy & $\mathrm{OP}$ & 9.5 \\
\hline 1964 & USA & DP & 5.1 & 1989 & S Arabia & $\mathrm{DP}$ & 2.2 & 2008 & Japan & PeDP & 9.8 \\
\hline 1965 & Israel & SC & 0.3 & 1989 & Ireland & - & 11.7 & 2008 & Brazil & PeDP & 4.8 \\
\hline 1966 & UK & OP & 4.3 & 1989 & Czechoslovakia & - & 4.1 & 2008 & Korea & OP & 11.2 \\
\hline 1963 & Canada & DP & 4.2 & 1990 & S Arabia & SC & 4.0 & 2009 & Spain & $\mathrm{OP}$ & 6.5 \\
\hline 1966 & USA & - & 6.5 & 1990 & Japan & PeDP & 16.2 & 2009 & Turkey & $\mathrm{DP}$ & 73.4 \\
\hline 1967 & USA & SC & 3.8 & 1990 & Thailand & $\mathrm{OP}$ & 8.6 & 2010 & Pakistan & $\mathrm{OP}$ & 9.0 \\
\hline 1967 & USA & SC & 4.1 & 1990 & Australia & DF & 6.3 & 2010 & India & $\mathrm{DP}$ & 0.1 \\
\hline 1968 & Australia & SC & 5.9 & 1990 & Ireland & $\mathrm{OP}$ & 11.3 & 2010 & Iran & DP & 9.0 \\
\hline 1968 & Denmark & SC & 6.1 & 1990 & Yugoslavia-Istria & $\mathrm{OP}$ & 6.3 & 2010 & Turkey & OP & 4.6 \\
\hline 1970 & USA & St & 3.5 & 1990 & Yugoslavia-Slavonia & $\mathrm{OP}$ & 2.3 & 2010 & Spain & PHS & 7.3 \\
\hline 1970 & USA & St & 3.6 & 1991 & Italy & DF & 3.6 & 2010 & Iran & OP & 9.1 \\
\hline 1971 & Finland & SC & 8.0 & 1992 & Japan & $\mathrm{OP}$ & 10.9 & 2010 & S Arabia & $\mathrm{OP}$ & 7.0 \\
\hline 1971 & - & - & 5.5 & 1992 & - & $\mathrm{OP}$ & 5.3 & 2010 & Turkey & $\mathrm{DP}$ & 1.5 \\
\hline 1971 & Sweden & SC & 6.3 & 1993 & Norway & SC & 6.5 & 2011 & Korea & $\mathrm{OP}$ & 11.3 \\
\hline 1972 & Japan & SC & 9.2 & 1994 & Germany & $\mathrm{OP}$ & 8.1 & 2011 & Korea & $\mathrm{DP}$ & 5.7 \\
\hline 1972 & Japan & $\mathrm{OP}$ & 11.0 & 1995 & Japan & PeDP & 2.8 & 2011 & India & $\mathrm{DP}$ & 4.5 \\
\hline 1973 & Israel & - & 4.6 & 1996 & Mexico & $\mathrm{OP}$ & 6.3 & 2011 & Germany & OP & 13.1 \\
\hline 1973 & Denmark & - & 8.2 & 1997 & Iceland & SC & 4.3 & 2012 & Iran & OP & 9.0 \\
\hline 1973 & Norway & SC & 10.1 & 1997 & Estonia & SC & 14.0 & 2012 & India & SC & 0.3 \\
\hline 1973 & Sweden & SC & 6.1 & 1998 & China & - & 7.3 & 2012 & Turkey & PeDP & 6.2 \\
\hline 1974 & UK & SC & 4.4 & 1999 & S Arabia & $\mathrm{DP}$ & 4.2 & 2012 & Portugal & $\mathrm{DP}$ & 6.1 \\
\hline 1974 & Switzerland & SC & 7.7 & 1999 & Brazil & $\mathrm{OP}$ & 6.3 & 2012 & S Arabia & $\mathrm{DP}$ & 4.7 \\
\hline 1974 & Norway & SC & 6.8 & 1999 & Japan & $\mathrm{OP}$ & 9.4 & 2012 & Iran & OP/DP & 10.9 \\
\hline
\end{tabular}

DS, dental student; OP, orthodontic patients; SC, schoolchildren; PuDP, public dental patients; PeDP, pediatric dental patients; DF, defense force recruits; PHS, attendees to the primary health services; DP, dental patients other than orthodontic patients.

From the study of Ghaznawi et al. [74], third molars were excluded by the author. Osuji et al. [81] reported only the missing of teeth anterior to molars. The sample of Sheikhi et al. [121] and Gabris et al. [85] were composed of both dental and orthodontic patients but the ratio of each was not known. A research had reported the maximum age as both 25 and 53 in different parts of the article [121]. Their maximum age was not used in analyses.

\section{Homogeneity of metadata}

Data were heterogeneous $\left(Q=7287.8, I^{2}=98.5, P=0.000\right)$ meaning that besides the sampling error due to the 
differences in the samples, other factors accounted for the different results as well.

\section{The biasing role of sample types}

Studies on orthodontic patients might report prevalence rates about $1 \%$ greater, while those of dental patients might report prevalence rates about $2 \%$ smaller than epidemiological studies (Figure 1). The Kruskal-Wallis test showed that the difference between reports on epidemiological samples versus orthodontic and dental patients is significant $(P=0.000)$. The Mann-Whitney $U$ test showed that the pairwise comparisons were as well significant between epidemiological samples with dental patients $(P=0.007)$ and orthodontic patients $(P=0.009)$, and also between orthodontic and non-orthodontic dental patients $(P=0.000$, corrected $\alpha=0.016)$.

\section{Compositions of samples in terms of sex balance}

The Spearman coefficient showed a significant correlation between CMT prevalence and male/female ratios (calculated by dividing the number of male subjects by females subjects) $(n=62, \rho=-0.407, P=0.001)$.

\section{Minimum age of included subjects}

The minimum age was not significantly correlated with CMT ( $n=79, \rho=-0.131, P=0.255$, Figure 2 ). Each minimum age was used as a cutoff to examine whether at any specific minimum age, there is a possibility to see significant differences between the CMT reported by studies adopting subjects younger and older than that age (Table 3). The comparisons were done using an unpaired $t$ test with Welch correction. An almost steady reduction was seen for most of the cutoffs, between studies adopting subjects with minimum ages less than each cutoff and those enrolling minimum ages over that cutoff. At the age of 10 (comparing $<10$ with $\geq 10$ ), the CMT prevalence was significantly different between studies with minimum ages set at less than 10 and those at 10 or older $(P=0.018)$. This also happened at the age $11(P=0.028)$ and $12(P=0.033)$. The highest difference was observed at the age of 13 , but it was only marginally significant (Table 3).

\section{Maximum age of included subjects}

The Spearman coefficient showed no significant correlation between the maximum ages and CMT prevalence ( $n=73, \rho=-0.003, P=0.978)$. Ages 15, 20, 25, 30, 35, 40,45 , and 50 were considered potential cutoffs. The comparison of the results of studies with maximum ages of patients less than or above these cutoff ages showed no significant differences. An outlier study with $\mathrm{CMT}=71.38 \%$ was in the analysis. After removing the outlier, the rest were re-analyzed. Although the results were nonsignificant, at the cutoff maximum age of 45 years, the $P$ value showed a peak from values $>0.8$ to 0.242 , and the difference changed from about $0.5 \%$ to $2 \%$ but still nonsignificant (i.e., the studies enrolling older ages showed about $2 \%$ greater CMT rates).

\section{Sample size as a biasing factor}

The sample size was significantly and negatively correlated with CMT ( $n=109, \rho=-0.250, P=0.009$ ).

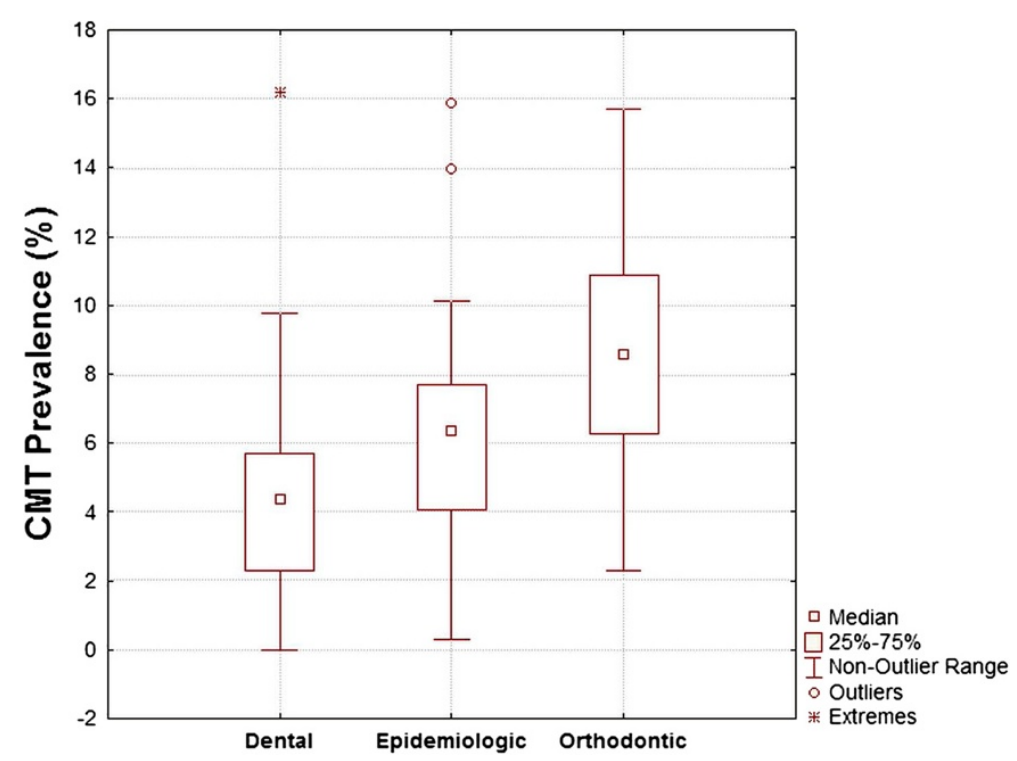

Figure 1 Box plots for different CMT prevalence rates in three population types. Taking into analysis 43 epidemiological studies, 32 studies of orthodontic patients, and 29 studies on dental patients. Pediatric dental patients are categorized as dental patients. 


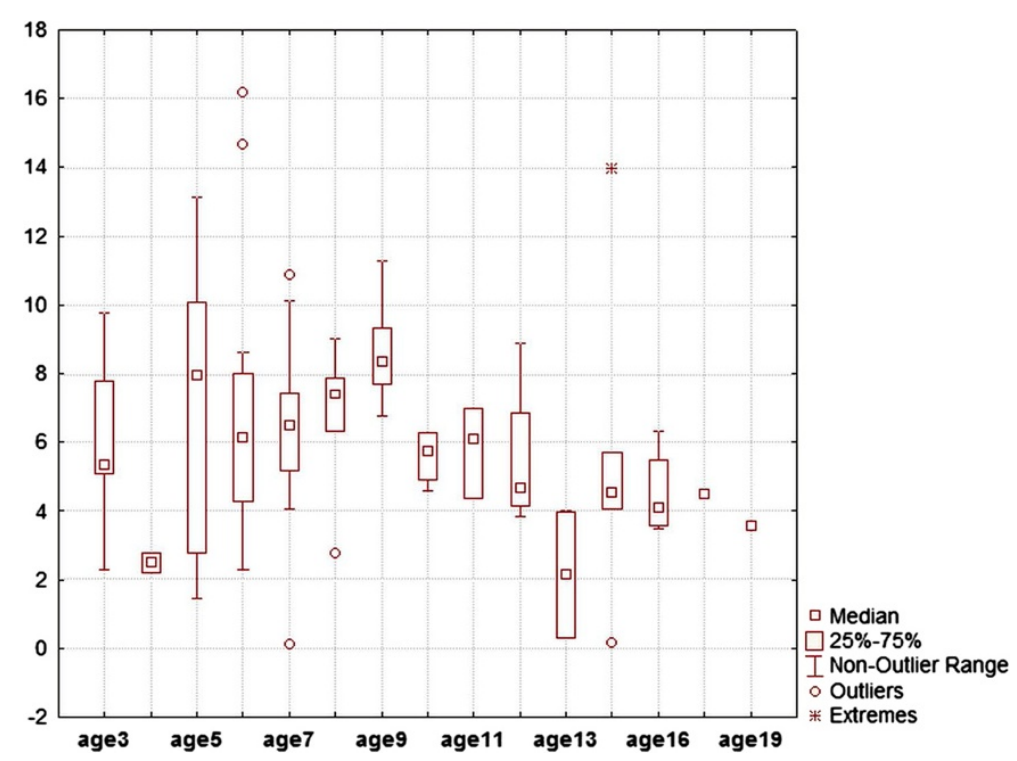

Figure 2 Box plots illustrating CMT of studies with different minimum ages of subjects.

\section{Publication bias}

By analyzing the potential asymmetry in the funnel plot (Figure 3), the Egger regression test pointed to a marginally significant publication bias (intercept $=2.81, \mathrm{SE}=$ $1.55,95 \% \mathrm{CI}=-0.26$ to $5.90, P=0.073)$.

\section{Correlation between scientific level of journals and the reported CMT prevalence}

The one study published in two different journals was considered as Pubmed-indexed. The outlier study of Peker et al. [91] was excluded from the analysis. There was no significant link between the credit of the article and the CMT prevalence reported ( $n=107, \rho=0.132, P=0.177$ ). The same analysis was done for studies published after

Table 3 Results of Welch $\boldsymbol{t}$ test comparing studies' CMT results (\%) according to various minimum ages

\begin{tabular}{|c|c|c|c|c|c|c|}
\hline \multirow{2}{*}{$\begin{array}{l}\text { Cutoff } \\
\text { age } \\
\text { (year) }\end{array}$} & \multicolumn{2}{|c|}{$<$ Cutoff } & \multicolumn{2}{|c|}{$\geq$ Cutoff } & \multirow[b]{2}{*}{ Difference } & \multirow[b]{2}{*}{$P$ value } \\
\hline & $N$ & Mean (\%) & $N$ & Mean (\%) & & \\
\hline 6 & 13 & 5.85 & 64 & 6.27 & 0.42 & 0.704 \\
\hline 7 & 28 & 6.41 & 49 & 6.08 & -0.33 & 0.687 \\
\hline 8 & 37 & 6.39 & 40 & 6.02 & -0.36 & 0.62 \\
\hline 9 & 42 & 6.42 & 35 & 5.93 & -0.49 & 0.49 \\
\hline 10 & 50 & 6.77 & 27 & 5.14 & -1.64 & 0.018 \\
\hline 11 & 54 & 6.68 & 23 & 5.06 & -1.63 & 0.028 \\
\hline 12 & 57 & 6.64 & 20 & 4.94 & -1.70 & 0.033 \\
\hline 13 & 64 & 6.52 & 13 & 4.60 & -1.92 & 0.074 \\
\hline 14 & 66 & 6.39 & 11 & 5.05 & -1.34 & 0.239 \\
\hline 16 & 71 & 6.34 & 6 & 4.50 & -1.84 & 0.011 \\
\hline
\end{tabular}

$\mathbf{N}$ number of studies.
1990 , and the association was still nonsignificant $(n=$ 54, $\rho=0.182, P=0.188)$.

\section{Discussion}

The literature consists of so many studies on the prevalence of CMT in permanent dentition (excluding third molars) among different populations [1,3-13,16-109,114,123-125]. The results are extremely controversial, ranging from $0.1 \%$ to $16.2 \%$ and varying considerably in many countries. However, they mostly revolved around $7 \%$ [mean $=6.72 \pm$ $3.28, n=110$ (excluding one unreliable outlier showing $74 \%)]$ [1,3-13,16-109]. The different rates reported could be explained by the ethnic backgrounds $[4,18,54,100,112,117,118]$ and variations in the samples with respect to sample sizes, types, and other biasing

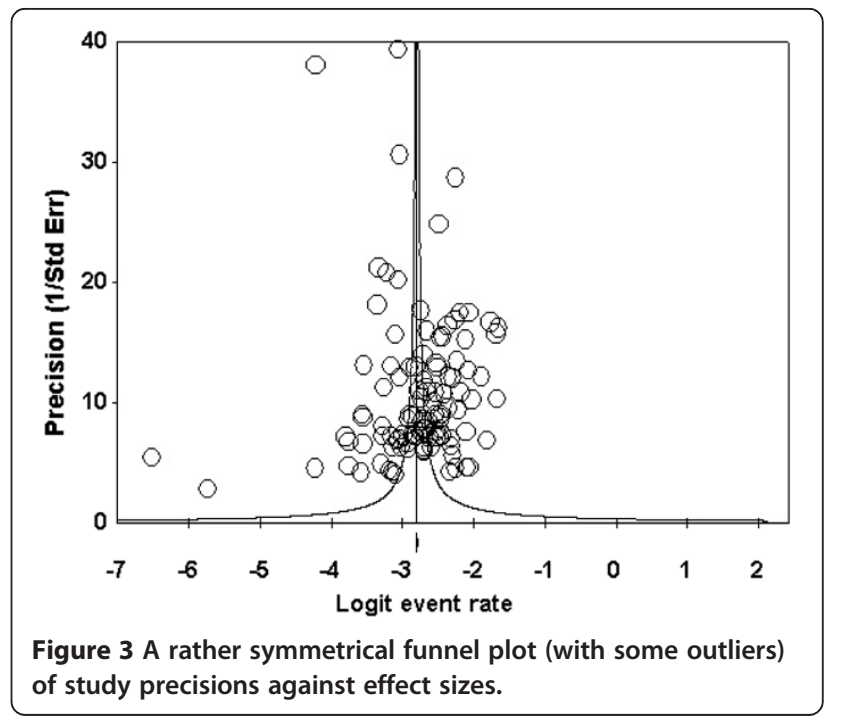


factors [2,3,18,86,117]. Another (unpublished) metaanalysis of this author shows that CMT may happen more in Yellow race and perhaps in Europeans, while it is less common in the west of Asia and America. Also this anomaly is not being increased in epidemiological samples through time, although inclusion of dental patients in recent studies is biasing this results ( $\mathrm{V}$ Rakhshan, unpublished work). The variations are not only a reflection of ethnicity, but can occur due to biasing factors as well. Discerning the responsible sources of bias can benefit future studies.

\section{Should studies be sex-balanced?}

Samples not balanced in terms of gender can bias the result, as CMT is more likely to occur in females $[10,11,17,35,36,50,82,83,91,100,117,119]$ (V Rakhshan, unpublished work). Our statistical analysis confirmed the role of the male/female ratio in affecting the prevalence. This ratio was considerably different from 1.0 in many studies (Figure 4). Such designs should be avoided in the future.

\section{Do minimum and maximum ages of included subjects matter?}

Calcification of teeth usually completes until the age of 9 years. Sometimes calcification of premolars is delayed $[18,69,74,86]$. The absence of a premolar in a radiograph cannot be certainly regarded as missing until this age, or the age of 10 years [117], particularly in boys [18,77,86,98,102]. Therefore, patients should be assessed in the third and fourth dental stages (DS), during which canines/premolars erupt and occlude with their antagonist teeth, respectively [102]. Inclusion of DS 1 and DS 2 (eruption and occlusion of incisors) and earlier stages should be avoided [102]. Some evidences clearly confirm the decrease of the observed CMT prevalence in a single population after 2 years (7-year old children compared to themselves at the age of 9) $[18,48,86]$. This can compromise studies which have enrolled subjects as young as $5[100,126]$ or 7 years old $[4,121]$. It probably causes high prevalence of second mandibular premolar missing (and also general CMT) $[3,10,17,48,117]$. Second premolars can develop long after what it would be ordinarily expected, reducing the degree of certainty [3]. Therefore, some authors have recommended exclusion of children younger than 7 [3], 9 or 10 years old $[18,77,86,98,117]$, or even under 16 [18]. Nevertheless, some authors refuted this by following a population of 7-year-old children evaluated first in 1976 until 1990 [4]. They found that only one out of 739 subjects showed late mineralization of teeth. They concluded that samples with minimum ages lower than 9 might as well lead to reliable results [4]. Also Varela et al. [75] assessed children under 10 years

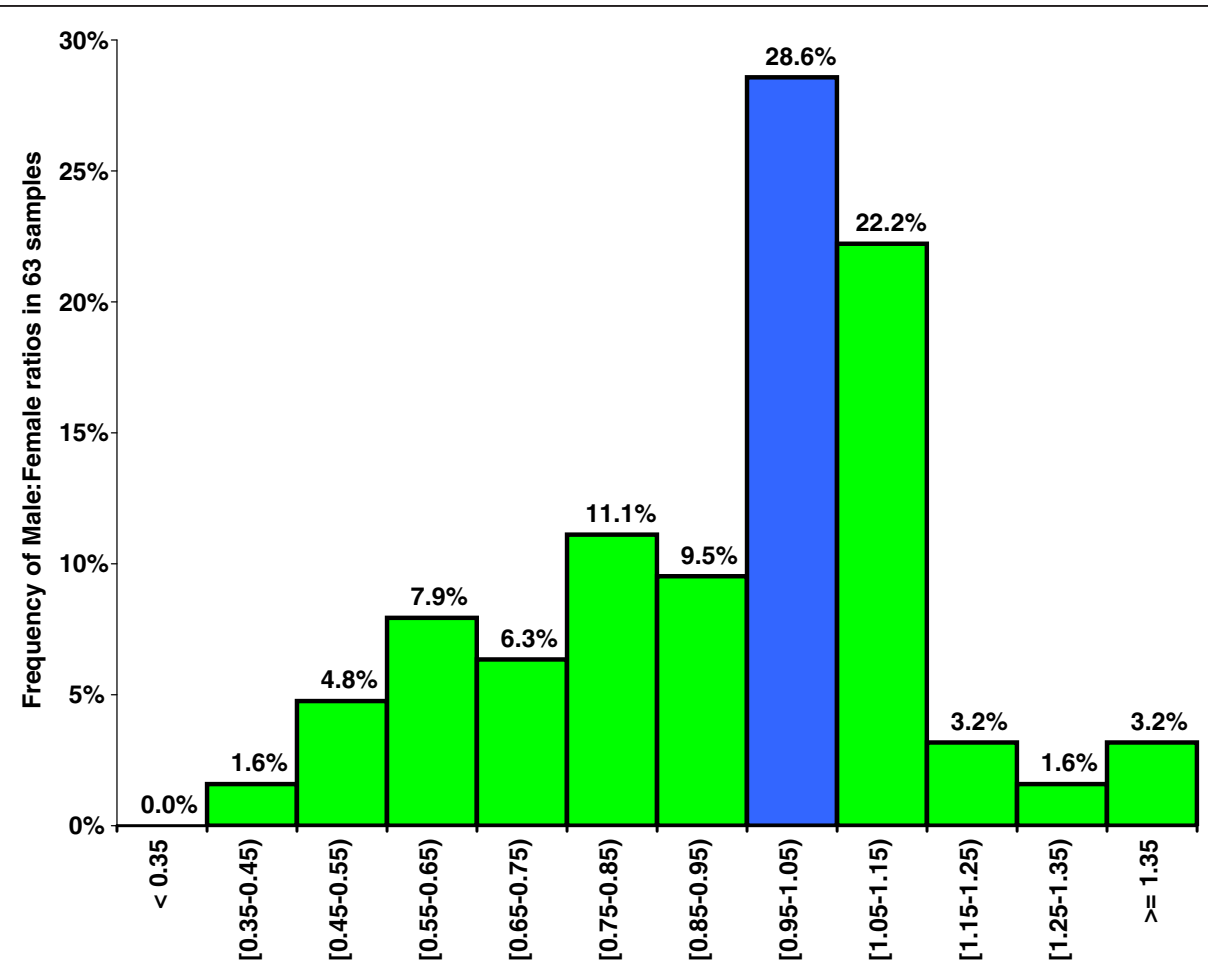

Figure 4 Frequency distribution of 63 ratios of enrolled male and female subjects. Frequency distribution (\%) of 63 ratios of enrolled male and female subjects, excluding one study with a male/female ratio of 4.21 [16] and two studies on only males [61,66]. The blue bar is indicative of gender-balanced samples. Ratios greater than 1 show a gender imbalance in favor of males, and those smaller than 1 denote more females. 
old with dental agenesis some years later and found no tooth germs in the place of previously found missing teeth [75].

Polder et al. [117] evaluated the prevalence reported in 33 studies stratified into those with older and younger than a minimum inclusion age of 7 years old. They did not find a significant difference $(P=0.42)$. The same happened in our study, when ages $6,7,8$, and 9 were the cutoff ages. Nevertheless, we investigated more ages as cutoffs. The post-cutoff decrease reached the level of significance when it came to the ages 10, 11, and 12 . Therefore, it seems that by enrolling people older than these ages, overestimation of CMT (due to false positive diagnosis of missing) is considerably reduced and these can be possibly considered of the best minimum ages. However, at older ages such as 16 as well, significant differences emerged, which imply that false positive diagnosis might occur even until 16. Since the number of subjects at a minimum age set by each study is not known, the mentioned minimum age does not necessarily reflect that a considerable part of a sample are at that minimum age or around it. This can blur the link between the stated minimum age and CMT. However, there was still a reduction (even if nonsignificant) for almost all the cutoff ages. It validates the claim that there might be a share of false positive in younger ages (which can be generalized at ages 10 to 12). It might be recommended to avoid the inclusion of subjects younger than 12 or 13 , in order to make sure an empty space seen in the radiograph at that age is almost only a case of missing, not a delayed tooth bud development. Of course sampling from older ages (such as older than 16) is better [18], but this has a trade off with the ease of finding proper test subjects.

It was hypothesized that perhaps enrolling older subjects might increase the false positive error due to the addition of the extracted teeth into the sample. Two reasons are imaginable for the lack of significance. First, many studies enrolled only full sets of dentition (regardless of patients' age). Second, a few studies had high maximum ages.

\section{Do orthodontic or other dental patients necessarily show 'greater' missing rates?}

It is suggested that children with CMT may be more prone to visit orthodontists compared to individuals without missing, which this can affect the findings $[5,17,18,37,86,125,127]$. However, Sisman et al. [86] showed that CMT prevalence is similar for orthodontic patients and epidemiological populations. On the other hand, our analyses showed that studies of orthodontic and other dental patients might have a slight but still statistically significant error (Figure 1). It was interesting that the prevalence rates reported by studies on dental patients (except orthodontic patients) were unexpectedly smaller than epidemiological samples. It seems that enrolling orthodontic patients should be accompanied with enrolling dental patients in similar ratios, in order to possibly offset or reduce their biasing roles at opposite directions. However, this needs further studies.

\section{Do smaller studies report higher prevalence?}

It might be plausible that when fewer research subjects are available, there might be a bias to catch more cases of interest. Also in larger studies, it is possible that exhausted researchers overlook some of existing cases. As well, small studies with low prevalence of dental agenesis might be less likely to be submitted or accepted for publication [117]. Therefore, smaller studies might show larger prevalence rates. Our findings confirmed that the sample size correlates negatively with the CMT. It is not easily known, however, whether the smaller prevalence rates are closer to reality or the greater ones, because there is no gold standard to estimate the sensitivity and specificity of these two and conduct receiveroperator curves. However, it can be recommended that sufficiently large samples (based on a priori power calculation) should be assessed by two or more observers. This way, the advantages of a larger sample remain while the odds of false negative errors reduce.

\section{Do greater CMT prevalence rates have better chances of being published?}

It was suggested that smaller samples with smaller CMT rates might have less chances to be published [117]. Our analysis could not verify this, although a marginally significant asymmetry was detected in the funnel plot. This lack of significant publication bias could be due to the rather more extensive literature search done in this study, which allowed many non-English and average articles to be pooled. Therefore, the author tried to assess whether such a trend exists. A higher chance of publication can increase the publication likelihood in acclaimed journals. So if better journals published higher CMT prevalence rates, the above assumption might be confirmed. Also since many studies published in the previous century were reported in accredited but not indexed journals, we repeated this analysis for studies published after 1990 (when the Pubmed and WoS databases were more popular in dental literature). Nevertheless, although the correlation increased slightly, it was still nonsignificant (in part due to the reduction in the new sample size). Therefore, we could not verify that if higher CMT prevalence rates have a greater chance of publication. It should be noted that although we tried to include local journals as well (if found by searching), there might be still many studies ruled out in this meta-sample due to the language bias. 


\section{Other potential limitations and sources of bias}

A limiting obstacle is the difficulty to accurately distinguish the absent tooth from adjacent similar teeth [102]. This is noticeable especially in the case of mandibular incisors when there are three incisors [3,18,102], for which meticulous examination of dental casts can be helpful $[89,102]$. It can be more difficult when the other teeth have moved, and also when the image of the vertebrae is superimposed on the anterior mandible [3].

Clinical examinations may cover merely $70 \%$ of actual cases of CMT, and radiographic examination is always necessary $[3,18,93]$. However, X-ray exposure for whatever purposes except treatment is unethical (even screening, since it is not effective [57]) $[18,116]$. Besides, orthodontic materials are appropriate for diagnosing CMT [89]. Therefore, recent papers are enrolling only orthodontic or dental patients. Our analyses showed that orthodontic patients or dental patients might show about $1 \%$ to $2 \%$ error compared to epidemiological samples, but there seems to be no other choice. Some studies enrolled epidemiological populations but reduced the number of radiographs taken, by clinically examining the area at first and ordering X-ray exploration if in doubt. Nevertheless, this method might introduce sampling bias [117].

\section{Why should definitions be unified?}

Another issue can be the variation in definitions. Specific terminologies are used to describe the nature of tooth agenesis. In general, the term hypodontia is most commonly used to describe the phenomenon of CMT [83]. Many other terms to describe a reduction in the number of teeth appear in the literature: oligodontia, anodontia, aplasia of teeth, congenitally missing teeth, absence of teeth, lack of teeth, and agenesis of teeth [83]. Hypodontia, oligodontia, and anodontia differ in terms of the number of missing teeth. Nevertheless, there is no clear consensus over the threshold differentiating hypodontia from oligodontia $[3,100,114]$. The categories used for defining oligodontia is the absence of more than three $[16,113]$, more than four $[5,89]$, more than five $[3,15,48,79,91,96,100,102,105,114,117,118,128]$, more than six teeth $[82,83,98,104,114]$, and even more than ten teeth $[69,129]$, always excluding the third molars [3]. Some authors did not define their threshold [1].

In some studies, the problem was beyond using different definitions. They basically confused the terms. For example, some investigators reported CMT under the name hypodontia $[4,19,75,77,89,90,94,98,102,106]$. A study reported hypodontia as CMT [109]. Some even reported oligodontia cases as a part of hypodontia (again implying that hypodontia was considered CMT) $[98,102]$. A study considered hypodontia as people with missing cases less than six teeth but more than two [105]. Some studies did not give any clear clue as if they were referring to CMT by hypodontia or not $[4,75,106,130]$. In some of them, there were certain vague (but not official) remarks implying that perhaps the CMT was the case [4,75,130]. All of the above-mentioned variations can account for the high heterogeneity observed in this meta-sample.

It might seem that the percentages reported by the erroneous definitions should be similar usually, as oligodontia has a low frequency. For example, two studies which mistook CMT with hypodontia, showed only one subject with more than six absent teeth [4] or even not more than six missing teeth [77]. Therefore, their CMT results [77] might be pointing to hypodontia as well. Besides, since the prevalence of missing of four or more teeth is scarce, changing the threshold of hypodontia definition from $>3$ teeth to $>6$ teeth might lead to slight changes only.

Nevertheless, in some populations, it can still account for some more vivid changes. About $10 \%$ to $25 \%$ of hypodontia cases are individuals with more than two teeth missing [4-6,8,10,13,17,18,27,36,40,41,46,48-50,53,54,62,76, $77,79,81,86,88,89,102,106,117,125,127]$. About 5\% of the population might have more than three missing teeth [89] or about $5.5 \%$ might have four and about $1.5 \%$ might have five absent teeth [86]. There can be about $6 \%$ and $5.4 \%$ prevalence of patients with four and five teeth missing, respectively in Japanese [3], about 7\% prevalence for four missing teeth in Brazil [88], 7\% prevalence of more than five missing teeth in Turkey [91], or $16 \%$ of more than five absent teeth in Germany [105]. Therefore, the unification of these terminologies as CMT instead of hypodontia etc., and using standardized templates to clearly define CMT and mild, moderate, and severe cases of CMT or hypodontia are necessary.

\section{Conclusions}

Limitations of previous reports make comparisons difficult and at some points impossible. A need for a standardized template is perceived to unify methodologies and also enable researchers to assess this issue with the most possible details.

Future studies should use standardized cutoff values for defining CMT/hypodontia and also standard methods for sampling and diagnosis. Future metaanalyses should include studies on orthodontic/dental patients as well, since due to the ethical concerns regarding X-ray exposure, epidemiological studies are unlikely affordable. Sampling from orthodontic patients might be preferable over dental patients or pediatric dentistry patients. This is because CMT results of orthodontic samples were closer to the epidemiological samples. However, it might be recommended to sample from both simultaneously, as their roles in biasing the prevalence are opposite of each other. Studies should 
not enroll children younger than 12 years. There seems to be no limit over the maximum age at least as long as positive extraction history is an exclusion criterion. It is recommended to adopt sufficiently large samples (based on power calculations) because of its obvious advantages. But since observers might miss some cases in such samples, two or more examiners should judge large samples to reduce or eliminate the corresponding false negative error. There seems to be no strong publication bias for accepting higher CMT prevalence rates.

\section{Abbreviation}

CMT: Congenital missing of teeth.

\section{Competing interests}

The author declares that he has no competing interests.

\section{Author's contributions}

The conception, design, reviews, statistical analyses, interpretations, drafting and preparation of this article were carried out by the author.

Received: 17 May 2013 Accepted: 5 July 2013

Published: 1 October 2013

\section{References}

1. Altug-Atac AT, Erdem D. Prevalence and distribution of dental anomalies in orthodontic patients. Am J Orthod Dentofacial Orthop. 2007; 131:510-4.

2. De Coster PJ, Marks LA, Martens LC, Huysseune A. Dental agenesis: genetic and clinical perspectives. J Oral Pathol Med. 2009; 38:1-17.

3. Goya HA, Tanaka S, Maeda T, Akimoto Y. An orthopantomographic study of hypodontia in permanent teeth of Japanese pediatric patients. J Oral Sci. 2008; 50:143-50.

4. Bäckman B, Wahlin YB. Variations in number and morphology of permanent teeth in 7-year-old Swedish children. Int J Pediatr Dent. 2001; 11:11-7.

5. Endo T, Ozoe R, Kubota M, Akiyama M, Shimooka S. A survey of hypodontia in Japanese orthodontic patients. Am J Orthod Dentofacial Orthop. 2006: 129:29-35.

6. Castaldi CR, Bodnarchuk A, MacRae PD, Zacherl WA. Incidence of congenital anomalies in permanent teeth of a group of Canadian children aged 6-9. J Can Dent Assoc (Tor). 1966; 32:154-9.

7. Helm S. Malocclusion in Danish children with adolescent dentition: an epidemiologic study. Am J Orthod. 1968; 54:352-66.

8. McKibben DR, Brearley $L$ J. Radiographic determination of the prevalence of selected dental anomalies in children. ASDC J Dent Child. 1971; 28:390-8.

9. Thilander $B$, Myrberg N. The prevalence of malocclusion in Swedish schoolchildren. Scand I Dent Res. 1973: 81:12-21.

10. Bergström K. An orthopantomographic study of hypodontia, supernumeraries and other anomalies in school children between the ages of 8-9 years. An epidemiological study. Swed Dent J. 1977; 1:145-57.

11. Brook AH. Dental anomalies of number, form and size: their prevalence in British school children. J Int Assoc Dent Child. 1974; 5:37-53.

12. Locht S. Panoramic radiographic examination of 704 Danish children aged 9-10 years. Community Dent Oral Epidemiol. 1980; 8:375-80.

13. Johannsdottir B, Wisth PJ, Magnusson TE. Prevalence of malocclusion in 6year-old Icelandic children. Acta Odontol Scand. 1997; 55:398-402.

14. Salem G. Prevalence of selected dental anomalies in Saudi children from Gizan region. Community Dent Oral Epidemiol. 1989; 17:162-3.

15. Pemberton TJ, Das P, Patel PI. Hypodontia: genetics and future perspectives. Braz J Oral Sci. 2005; 4:695-709.

16. Lynham A. Panoramic radiographic survey of hypodontia in Australian Defence Force recruits. Aust Dent J. 1990; 35:19-22.

17. Nik-Hussein NN. Hypodontia in the permanent dentition: a study of its prevalence in Malaysian children. Aust Orthod J. 1989; 11:93-5.

18. Amini F, Rakhshan V, Babaei P. Prevalence and pattern of hypodontia in the permanent dentition of 3374 Iranian orthodontic patients. Dent Res J (Isfahan). 2012; 9:245-50.
19. Moon HS, Choi SC, Choung PH. Hypodontia and hyperdontia of permanent teeth in Korean schoolchildren. Cleft Lip and Palate Assoc 2001; 4:19-27.

20. Dolder E. Deficient dentition. Dent Pract Dent Rec. 1936; 57:142-3.

21. Werther R, Rothenberg F. Anodontia: a review of its etiology with presentation of a case. Am J Orthod. 1939; 25:61-81.

22. Byrd ED. Incidence of supernumerary and congenitally missing teeth. J Dent Child. 1943: 10:84-6.

23. Ma C. Statistical observation of morphological and numerical teeth anomalies in the teeth of Japanese. Shikagaku Zasshi. 1949; 6:248-56.

24. Okamoto O, Mori O, Morimoto M, Nakao N, Miyakawa E. A statistical and genetic study related to congenital missing teeth. Shika Gakuho. 1951; 5:8-10.

25. Terasaki T, Shiota K. Congenital absence of teeth. Nihon Kokyuki Gakkai Zasshi. 1954; 3:88-93.

26. Tsutsui H, Yoshida Y. Clinical statistical study on supernumerary teeth and congenital absence of teeth. Kokubyo Gakkai Zasshi. 1955; 22:44-8.

27. Grahnén H. Hypodontia in the permanent dentition: a clinical and genetical investigation. Odont Revy. 1956; 7:1-100.

28. Clayton JM. Congenital dental anomalies occurring in 3557 children. J Dent Child. 1956; 23:206-8.

29. Lind V. Medfödda antalsvariationer i permanenta dentitionen. Odont Revy. 1959; 10:176-89.

30. Glenn F. Incidence of congenitally missing permanent teeth in a private pedodontic practice. ASDC J Dent Child. 1961; 28:317-20.

31. Gimnes H. En frekvensundersøkelse over hypodonti hos skolebarn i Oslo, med saerlig henblikk på forekomst av bilateral hypodonti av 2. premolar i underkjeven. Nor Tannlaegeforen Tid. 1963; 73:141-8.

32. Volk A. Über die Häufigkeit des Vorkommens von fehlenden Zahnanlagen. Schweiz Monatsschr Zahnmed. 1963; 73:320-34.

33. Niswander JD, Sujaku C. Congenital anomalies of teeth in Japanese children. Am J Phys Anthropol. 1963: 21:569-74.

34. Glenn FB. A consecutive six-year study of the prevalence of congenitally missing teeth in private pedodontic practice of two geographically separated areas. ASDC J Dent Child. 1964; 3:264-70.

35. Rosenzweig KA, Garbarski D. Numerical aberrations in the permanen teeth of grade school children in Jerusalem. Am J Phys Anthropol. 1965; 23:277-83.

36. Rose JS. A survey of congenitally missing teeth, excluding third molars, in 6000 orthodontic patients. Dent Pract Dent Rec. 1966; 17:107-14.

37. Horowitz JM. Aplasia and malocclusion: a survey and appraisal. Am J Orthod. 1966; 52:440-53.

38. Blayney J, Hill I. Congenitally missing teeth. J Am Dent Assoc. 1967; 74:298-9.

39. Davies PL. Agenesis of teeth of the permanent dentition: a frequency study in Sydney schoolchildren. Aust Dent J. 1968; 13:146-50.

40. Muller TP, Hill IN, Peterson AC, Blayney JR. A survey of congenitally missing permanent teeth. J Am Dent Assoc. 1970; 81:101-7.

41. Haavikko K. Hypodontia of permanent teeth. An orthopantomographic study. Suom Hammaslaak Toim. 1971; 67:219-25.

42. Egermark-Eriksson I, Lind V. Congenital numerical variation in the permanent dentition. D. Sex distribution of hypodontia and hyperodontia. Odontol Revy. 1971; 22:309.

43. Hanaoka H, Yamauchi K, Kawasoko S, Imada Y. [Anomalies in number of teeth of orthodontic patients. 3. Relationship to malocclusion]. Nippon Kyosei Shika Gakkai Zasshi. 1972; 31:162.

44. Eidelman E, Chosack A, Rosenzweig KA. Hypodontia: prevalence amongst Jewish populations of different origin. Am J Phys Anthropol. 1973; 39:129-33.

45. Ravn JJ. Nielsen LA [Orthopantomographic study of supernumerary teeth and aplasia among 1530 Copenhagen school children]. Tandlaegebladet. 1973; 77:12-22.

46. Hunstadbraten K. Hypodontia in the permanent dentition. ASDC J Dent Child. 1973; 40:115-7.

47. Bachmann H. Die Häufigkeit von Nichtanlagen bleibender Zähne (ausgenommen der Weisheitszähne). Ergebnisse der Auswertung von 8694 Orthopantogrammen 910 Jährigen Schulkinder aus Zürich, dissertation. Zürich: University of Zürich; 1974

48. Wisth PJ, Thunold K, Böe OE. Frequency of hypodontia in relation to tooth size and dental arch width. Acta Odontol Scand. 1974; 32:201-6.

49. Thompson GW, Popovich F. Probability of congenitally missing teeth: results in 1,191 children in the Burlington Growth centre in Toronto. Community Dent Oral Epidemiol. 1974; 2:26-32. 
50. Magnússon TE. An epidemiologic study of dental space anomalies in Icelandic schoolchildren. Community Dent Oral Epidemiol. 1977; 5:292-300.

51. Nakahara M, Okada S, Tani H. [A survey of congenitally missing permanent teeth in Hokkaido]. Koku Eisei Gakkai Zasshi. 1977; 27:21.

52. Maklin M, Dummett CO Jr, Weinberg R. A study of oligodontia in a sample of New Orleans children. ASDC J Dent Child. 1979; 46:478-82

53. Rølling S. Hypodontia of permanent teeth in Danish schoolchildren. Scand J Dent Res. 1980; 88:365-9.

54. Davis PJ. Hypodontia and hyperdontia of permanent teeth in Hong Kong schoolchildren. Community Dent Oral Epidemiol. 1987; 15:218-20.

55. Ishizuka K, Sasaki T, Imai R, Nakamura N, Yoshida T, Anabuki M, Tashiro M, Maeda $K$, Uchida $Y$, Inoue $K$. Abnomalies of teeth which affects the orthodontic treatment. Nichidai Shigaku. 1988; 62:584-95.

56. Lai PY, Seow WK. A controlled study of the association of various dental anomalies with hypodontia of permanent teeth. Pediatr Dent. 1989; 11:291-6.

57. Lo Muzio L, Mignogna MD, Bucci P, Sorrentino F. Statistical study of the incidence of agenesis in a sample of 1529 subjects. Minerva Stomatol. 1989; 38:1045-51.

58. Ignelzi MA Jr, Fields HW, Vann WF Jr. Screening panoramic radiographs in children: prevalence data and implications. Pediatr Dent. 1989; 11:279-85.

59. Burden D, Connolly I. Radiographic study of hypodontia and other anomalies in orthodontic patients. J Dent Res. 1989; 68:295.

60. Renkerová M, Badura S, Manicová H, Jambor J. A contribution to anomalous number of teeth in children in the Zilina District. Praktické zubni lékar?ství. 1989; 37:12.

61. al-Emran S. Prevalence of hypodontia and developmental malformation of permanent teeth in Saudi Arabian schoolchildren. Br J Orthod. 1990; 17:115-8.

62. Yanagida I, Mori S. Statistical studies on numerical anomalies of teeth in children using orthopantomograms - congenital hypodontia. Osaka Daigaku Shigaku Zasshi. 1990; 35:580-93.

63. Dechkunakorn S, Chaiwat J, Sawaengkit P. Congenital absence and loss of teeth in an orthodontic patient group. J Dent Assoc Thai. 1990; 40:165.

64. O'Dowling IB, McNamara TG. Congenital absence of permanent teeth among Irish school-children. J Ir Dent Assoc. 1990; 36:136-8.

65. Legonic M, Ceranic I, Cehich A. Anomalies in the number of permanent teeth in orthodontic patients in 2 localities in Croatia. Schweiz Monatsschr Zahnmed. 1990; 100:286-90.

66. Polastri F, Cerato E, Gallesio C. The clinico-radiological assessment of dental anomalies with real and apparent numerical defects. Minerva Stomatol. 1991; 40:415-23.

67. Watanabe K, Motoyoshi M, Fukui R, Chang K, Namba Akira SM. A study on incidence of congenital missing of teeth among orthodontics patients. Nihon Univ Dent J. 1992; 66:1029-33 (in Japanese).

68. Cua-Benward GB, Dibaj S, Ghassemi B. The prevalence of congenitally missing teeth in class I, II, III malocclusions. J Clin Pediatr Dent. 1992; 17:15-7.

69. Aasheim B, Ogaard B. Hypodontia in 9-year-old Norwegians related to need of orthodontic treatment. Scand J Dent Res. 1993; 101:257-60.

70. Ogita S, Ogita M, Yamamoto T, Yanase H, Kondo YKY. The appearance of supernumerary teeth and congenitally missing teeth in 6299 Japanese pediatric patients. Aichi Gakuin Dent Sci. 1995; 33:19-27.

71. Cuairán RV, Gaitan ZL, Hernández MA. Agenesia dental en una muestra de pacientes ortodónticos del Hospital Infantil de México. ADM. 1996; 53:211-5.

72. Peltola JS, Wolf J, Mannik A, Russak S, Seedre T, Sirkel M, Vink M. Radiographic findings in the teeth and jaws of 14- to 17-year-old Estonian schoolchildren in Tartu and Tallinn. Acta Odontol Scand. 1997; 55:31-5.

73. Tsai SJ, King NM. A catalogue of anomalies and traits of the permanent dentition of southern Chinese. J Clin Pediatr Dent. 1998; 22:185-94.

74. Ghaznawi H, Daas H, Salako NO. A clinical and radiographic survey of selected dental anomalies and conditions in a Saudi Arabian population. 1999.

75. Varela M, Arrieta P, Ventureira C. Non-syndromic concomitant hypodontia and supernumerary teeth in an orthodontic population. Eur J Orthod. 2009; 31:632-7.

76. Hirukawa K, Iwata R, Kurosawa M, Kondo T, Goto S. Statistical investigation about the prevalence of congenitally missing permanent teeth. Orthodontic Waves. 1999; 58:49-56.
77. Ng'ang'a RN, Ng'ang'a PM. Hypodontia of permanent teeth in a Kenyan population. East Afr Med J. 2001; 78:200-3.

78. Gabris K, Tarjan I, Csiki P, Konrad F, Szadeczky B, Rozsa N. Prevalence of congenital hypodontia in the permanent dentition and its treatment. Fogorv Sz. 2001; 94:137-40

79. Nordgarden H, Jensen JL, Storhaug K. Reported prevalence of congenitally missing teeth in two Norwegian counties. Community Dent Health. 2002; 19:258-61.

80. Al-Nakib LH, Younis WH. Orthopantomographic survey of hypodontia among Iraqi orthodontic patients. J Coll Dent. 2002; 4:74

81. Osuji OO, Hardie J. Dental anomalies in a population of Saudi Arabian children in Tabuk. Saudi Dent J. 2002; 14:11-4.

82. Silva MR. Radiographic assessment of congenitally missing teeth in orthodontic patients. Int J Pediatr Dent. 2003; 13:112-6.

83. Fekonja A. Hypodontia in orthodontically treated children. Eur J Orthod. 2005; 27:457-60.

84. Albashaireh ZS, Khader YS. The prevalence and pattern of hypodontia of the permanent teeth and crown size and shape deformity affecting upper lateral incisors in a sample of Jordanian dental patients. Community Dent Health. 2006; 23:239-43.

85. Gábris K, Fábián G, Kaán M, Rózsa N, Tarján I. Prevalence of hypodontia and hyperdontia in paedodontic and orthodontic patients in Budapest. Community Dent Health. 2006; 23:80-2.

86. Sisman Y, Uysal T, Gelgor IE. Hypodontia. Does the prevalence and distribution pattern differ in orthodontic patients? Eur. J Dent. 2007; 1:167-73.

87. Galluccio G, Pilotto A. Genetics of dental agenesis: anterior and posterior area of the arch. Eur Arch Paediatr Dent. 2008; 9:41-5.

88. Kuchler EC, Risso PA, Costa Mde C, Modesto A, Vieira AR. Studies of dental anomalies in a large group of school children. Arch Oral Biol. 2008; 53:941-6.

89. Chung $\mathrm{CJ}$, Han $\mathrm{JH}$, Kim KH. The pattern and prevalence of hypodontia in Koreans. Oral Dis. 2008; 14:620-5.

90. Al-Ajwadi SAM. An orthopantomographic study of hypodontia in permanent teeth of Iraqi patients. Med Dent J. 2009; 6:139-4.

91. Peker I, Kaya E, Darendeliler-Yaman S. Clinic and radiographical evaluation of non-syndromic hypodontia and hyperdontia in permanent dentition. Med Oral Patol Oral Cir Bucal. 2009; 14:e393-7.

92. Uslu O, Akcam MO, Evirgen S, Cebeci I. Prevalence of dental anomalies in various malocclusions. Am J Orthod Dentofacial Orthop. 2009; 135:328-35.

93. Durrani OK, Zulfiqar K, Bashir U, Shamsher M. Prevalence of tooth agenesis in orthodontic patients at Islamic International Dental Hospital. Pakistan Orthod J. 2010; 2:48-51.

94. Guttal KS, Naikmasur VG, Bhargava P, Bathi RJ. Frequency of developmental dental anomalies in the Indian population. Eur J Dent. 2010; 4:263-9.

95. Ajami B, Shab ZM, Afzal Aghaei M, Mehrjerdian MC. Prevalence and pattern of congenital missing teeth in a group of Iranian adolescents. J Dent Shiraz Univ Med Sci. 2010; 10:40-4.

96. Celikoglu M, Kazanci F, Miloglu O, Oztek O, Kamak H, Ceylan I. Frequency and characteristics of tooth agenesis among an orthodontic patient population. Med Oral Patol Oral Cir Bucal. 2010; 15:e797-801. e797-801.

97. Tallón-Walton V, Nieminen P, Arte S, Carvalho-Lobato P, Ustrell-Torrent JM, Manzanares-Céspedes MC. An epidemiological study of dental agenesis in a primary health area in Spain: estimated prevalence and associated factors. Med Oral Patol Oral Cir Bucal. 2010; 15:e569-74.

98. Vahid-Dastjerdi E, Borzabadi-Farahani A, Mahdian M, Amini N. Nonsyndromic hypodontia in an Iranian orthodontic population. J Oral Sci. 2010; 52:455-61.

99. Aljazi Hussain AJ, Abdullah Mohammad A. A study on dento/skeletal discrepancies and dental anomalies in a sample of Saudi orthodontic patients, Thesis. King Saud University; 2010.

100. Aktan A, Kara I, Sener I, Bereket C, Ay S, Çiftçi M. Radiographic study of tooth agenesis in the Turkish population. Oral Radiol. 2010; 26:95-100.

101. Kositbowornchai S. Prevalence and distribution of dental anomalies in pretreatment orthodontic Thai patients. Khon Kaen Univ Dent J. 2011; 13:92-100.

102. Kim YH. Investigation of hypodontia as clinically related dental anomaly: prevalence and characteristics. ISRN Dent. 2011; 2011:246135.

103. Lee JH, Yang BH, Lee SM, Kim YH, Shim HW, Chung HS. A study on the prevalence of dental anomalies in Korean dental-patients. Korean J Orthod. 2011; 41:346-53. 
104. Gupta SK, Saxena P, Jain S, Jain D. Prevalence and distribution of selected developmental dental anomalies in an Indian population. J Oral Sci. 2011; 53:231-8.

105. Behr M, Proff $P$, Leitzmann M, Pretzel M, Handel G, Schmalz G, Driemel O, Reichert TE, Koller M. Survey of congenitally missing teeth in orthodontic patients in Eastern Bavaria. Eur J Orthod. 2011; 33:32-6.

106. Shetty P, Adyanthaya A, Adyanthaya S, Sreelatha SV. The prevalence of hypodontia and supernumerary teeth in 2469 school children of the Indian population: an epidemiological study. Indian J Stomatol. 2012; 3:150-2.

107. Cantekin K, Dane A, Miloglu O, Kazanci F, Bayrakdar S, Celikoglu M. Prevalence and intra-oral distribution of agenesis of permanent teeth among Eastern Turkish children. Eur J Paediatr Dent. 2012; 13:53-6.

108. Gonzalez-Allo A, Campoy MD, Moreira J, Ustrell J, Pinho T. Tooth agenesis in a Portuguese population. Int Orthod. 2012; 10:198-210.

109. Afify AR, Zawawi $\mathrm{KH}$. The prevalence of dental anomalies in the western region of Saudi Arabia. ISRN Dent. 2012; 2012:837270.

110. Shimizu T, Maeda T. Prevalence and genetic basis of tooth agenesis. Jpn Dent Sci Rev. 2009; 45:52-8.

111. Murdock S, Lee JY, Guckes A, Wright JT. A costs analysis of dental treatment for ectodermal dysplasia. J Am Dent Assoc. 2005; 136:1273-6.

112. Wu CC-L, Wong RW-K, Hägg U. A review of hypodontia: the possible etiologies and orthodontic, surgical and restorative treatment options conventional and futuristic. Hong Kong Dent J. 2007: 4:113-21.

113. Rune B, Sarnäs KV. Tooth size and tooth formation in children with advanced hypodontia. Angle Orthod. 1974; 44:316-21.

114. Gomes RR, da Fonseca JAC, Paula LM, Faber J, Acevedo AC. Prevalence of hypodontia in orthodontic patients in Brasilia, Brazil. Eur J Orthod. 2010; 32:302-6.

115. Larmour CJ, Mossey PA, Thind BS, Forgie AH, Stirrups DR. Hypodontia - a retrospective review of prevalence and etiology. Part I. Quintessence Int. 2005; 36:263-70.

116. Khosravanifard B, Rakhshan V, Raeesi E. Factors influencing attractiveness of soft tissue profile. Oral Surg Oral Med Oral Pathol Oral Radiol. 2013; 115:29-37.

117. Polder BJ, Van't Hof MA, Van der Linden FPGM, Kuijpers-Jagtman AM. A meta-analysis of the prevalence of dental agenesis of permanent teeth. Community Dent Oral Epidemiol. 2004; 32:217-26.

118. Nunn JH, Carter NE, Gillgrass TJ, Hobson RS, Jepson NJ, Meechan JG, Nohl FS. The interdisciplinary management of hypodontia: background and role of paediatric dentistry. Br Dent J. 2003; 194:245-51.

119. Brook $\mathrm{AH}$. A unifying aetiological explanation for anomalies of human tooth number and size. Arch Oral Biol. 1984; 29:373-8.

120. Mattheeuws N, Dermaut L, Martens G. Has hypodontia increased in Caucasians during the 20th century? A meta-analysis. Eur J Orthod. 2004; 26:99-103.

121. Sheikhi M, Sadeghi MA, Ghorbanizadeh S. Prevalence of congenitally missing permanent teeth in Iran. Dent Res J (Isfahan). 2012; 9:S105-11.

122. Ajami BA, Shabzendedar M, Mehrjerdian M. Prevalence of hypodontia in nine- to fourteen-year-old children who attended the Mashhad School of Dentistry. Indian J Dent Res. 2010; 21:549-51.

123. Tavajohi-Kermani H, Kapur R, Sciote JJ. Tooth agenesis and craniofacial morphology in an orthodontic population. Am J Orthod Dentofacial Orthop. 2002; 122:39-47.

124. Sterzik G, Steinbicker V, Karl N. The etiology of hypodontia. Fortschr Kieferorthop. 1994; 55:61-9.

125. Silverman NE, Ackerman JL. Oligodontia: a study of its prevalence and variation in 4032 children. ASDC J Dent Child. 1979; 46:470-7.

126. Salama FS, Abdel-Megid FY. Hypodontia of primary and permanent teeth in a sample of Saudi children. Egypt Dent J. 1994; 40:625-32.

127. Ringqvist $M$, Thilander $B$. The frequency of hypodontia in an orthodontic material. Sven Tandlak Tidskr. 1969; 62:535-41.

128. Schalk-van der Weide Y, Beemer FA, Faber JA, Bosman F. Symptomatology of patients with oligodontia. J Oral Rehabil. 1994; 21:247-61.
129. Ogaard B, Krogstad O. Craniofacial structure and soft tissue profile in patients with severe hypodontia. Am J Orthod Dentofacial Orthop. 1995; 108:472-7.

130. Ghaznawi HI, Daas H, Salako NO. A clinical and radiographic survey of selected dental anomalies and conditions in a Saudi Arabian population. Saudi Dent J. 1999; 11:8-13.

doi:10.1186/2196-1042-14-33

Cite this article as: Rakhshan: Meta-analysis and systematic review of factors biasing the observed prevalence of congenitally missing teeth in permanent dentition excluding third molars. Progress in Orthodontics $201314: 33$

\section{Submit your manuscript to a SpringerOpen ${ }^{\odot}$ journal and benefit from:}

- Convenient online submission

- Rigorous peer review

- Immediate publication on acceptance

- Open access: articles freely available online

- High visibility within the field

- Retaining the copyright to your article

Submit your next manuscript at $>$ springeropen.com 